\title{
The Geriatric Medication Game to Raise Community Pharmacists' Awareness on Older Adults' Day-to-Day Challenges
}

\author{
Aisha F. Badr \\ Department of Pharmacy Practice, College of Pharmacy, King Abdulaziz University, Jeddah, Saudi Arabia
}

\section{Keywords}

Geriatrics - Aged · Pharmacists - Deaf-blind disorders .

Pharmacy education - Empathy · Staff attitude · Education of patients

\begin{abstract}
Introduction: In Saudi Arabia; it is estimated that the elderly (aged 60 and above) would reach up to (22.9\%) by 2050, compared to (5.6\%) in 2017. Simulation games have proven to be a useful and effective method of education in pharmacy schools, as it actively involves participants in the learning process. The objective of this study was to examine the impact of the modified geriatric medication game on community pharmacists' awareness and attitudes toward older adults with common disabilities. Methods: A modified geriatric medication game was adopted to stimulate both physical and sensory disabilities in older adults. A total of 9 community pharmacists were gathered in 1 room and were asked to play 2 scenarios each. Self-reflection was assessed and ground theories were analyzed. Results: All pharmacists felt frustration and anger playing the game (100\%), followed by becoming more aware of the extra time and guidance needed with older adults and realized how disabling chronic diseases could be, and felt they needed to improve common perceived attitude towards the elderly (88.89\%). Phar-
\end{abstract}

karger@karger.com www.karger.com/sjh

Karger $\stackrel{\text { ' }}{5}$

GOPEN ACCESS
C 2021 The Author(s).

Published by S. Karger AG, Basel

This is an Open Access article licensed under the Creative Commons Attribution-NonCommercial-4.0 International License (CC BY-NC) (http://www.karger.com/Services/OpenAccessLicense), applicable to the online version of the article only. Usage and distribution for commercial purposes requires written permission. macists also felt empathy, sympathy, and compassion towards this population, needed improvement of common perceived attitude towards older adults, and felt the need to double check with older adults if they have any disabilities before counseling (77.78\%). Finally, over half pharmacists (55.5\%) wished they had more training on geriatrics during pharmacy school and the need for further review of Beer's criteria. All pharmacists were satisfied with the game and recommended it to all community pharmacists. Conclusion: Simulation games are a great way to strengthen awareness and change practice accordingly. Pharmacists improved their awareness and attitude towards the elderly and reported a positive perceived value of this learning activity; with a $100 \%$ satisfaction rate. Adding a geriatric course with simulation component is recommended for better geriatric care.

(c) 2021 The Author(s)
Published by S. Karger AG, Basel

\section{Introduction}

Globally older adults aged 60 and above are expected to double again by 2050 and is projected to reach nearly 1.2 billion. Moreover, the number of those 80 years and above is also thought to increase by more than 3 -fold between 2017 and 2050 and rising to 425 million in Saudi Arabia; it is estimated that the elderly (aged 60 and above)
Correspondence to:

Aisha F. Badr, afbadr@kau.edu.sa 
would reach up to $22.9 \%$ by 2050 , compared to $5.6 \%$ in 2017 [1]. Older adults are known to be the largest consumers of prescription medication, and with that pharmacists should be well aware of potential side effects, drug interactions, potentially inappropriate medications, and over-the-counter (OTC) supplements and herbs used in this population [2].

With the growing number of the elderly, we need to be professionally well prepared to address their needs and fully understand any limitations that may arise. Community pharmacists are described in many countries as the most easily accessible health professionals [3, 4]. Selecting the most appropriate medication, guided by STOP/ START and Beers criteria, is a great start, but grasping the elderly's physical and sensory limitations is vital to aid with our interaction and communication with this respectful community segment $[5,6]$. As a result, many pharmacy schools nationally and internationally have added a geriatric course to their curriculum in order to prepare the twenty-first century graduates to meet pharmaceutical needs of the older adult population [7]. However, previous graduates have had a little or no exposure to geriatric needs and no courses were implemented to address it. It is therefore, vital to assess community pharmacist preparedness and awareness of the geriatric pharmacokinetic and pharmacokinetic changes [8].

Simulation games have proven to be a useful and effective method of education, as it actively involves participants in the learning process [9-11]. Several games have been illustrated in research with the focus of simulating the aging process since 1984 [12]. A literature review on stimulation games and methods to assess pharmacist awareness and attitude towards older adults revealed 1 game that was developed by the St. Louis College of Pharmacy that specifically addressed sensory and physical medication-related challenges; which was: "The Geriatric Game" $[9,13]$. The objective of this study was to examine the impact of participation in the modified geriatric medication game on pharmacists' awareness and attitudes toward older adults with common disabilities that affect them.

\section{Methodology}

The Geriatric Medication Game - Objective

The following were the objectives:

- To raise pharmacists' perceptions and awareness toward older adults physical and sensory disabilities.

- To identify limitations occurring as a result of disabilities in older adults.
- To familiarize pharmacists with older adults' barriers faced when seeking medical advice.

- To practice empathy towards older adults.

- To change common practice accordingly.

The - Modified - Geriatric Medication Game - Design

The game was initially developed in 1979 by 2 faculties and 4 students at the university. In this stimulated experience, the player step in the shoes of a patient over the age of 65 years old; with physical, psychological, and financial problems while navigating through the healthcare system and tackling challenges [13].

In collaboration with a local retail pharmacy chain (Al Nahdi Medical Company) We invited community pharmacists working in Jeddah, Saudi Arabia to attend the simulated workshop that would be held during break time (12:00-1:00 p.m.); as a part of an awareness program on the elderly population. Al Nahdi Medical Company invited the community pharmacists and provided a big room that is located at one of their biggest branches in the central region of Jeddah, Saudi Arabia. Those who attended the simulation workshop voluntarily were included in the study.

The Geriatric Medication Game - Kit

Each table had one kit that contained the following: (1) 2 glaucoma goggles - simulator, (2) 2 sets of ear plugs, (3) 2 sets of latex gloves lined up from the inside with Birchwood flat spoon sticks, (4) an OTC medication (Panadol cold and flu - acetaminophen/ phenylephrine HCL), (5) prescription bottle with the label "take half a pill by mouth 30 min before meal," (6) glass bottle with thick juice (mango juice), and (7) 2 plastic spoons.

Each kit also provided cards with 5 different scenarios; with each scenario requiring one community pharmacist to counsel another presenting as a geriatric patient with either a physical or sensory barrier. Tasks were switched as the game proceed, so both can act out on each scenario as a patient and as the community pharmacist. Each table had 1 pharmacy intern to facilitate tasks.

\section{The Geriatric Medication Game - Scenarios}

1 Sensory Disability Simulated Scenarios

1a Vision Impairment

- Scenario \#1. Patient task: while wearing the glasses, read "Directions" of the medication label.

- Scenario \#2. Patient task: read carefully the instructions on the label.

1b Hearing Impairment

- Scenario \#3. Patient task: repeat after the pharmacist's instructions.

2 Physical Disability Simulated Scenarios

2a Arthritis

- Scenario \#4. Patient task: do as instructed wearing the gloves.

- Scenario \#5. Patient task: open the bottle, try to split the medication in half.

Pharmacists were asked at the end of the game to reflect on their experience navigating through the game and being in an older adults' shoes. Questions were adapted from previous research that used a modified version of this game (Table 1) [14]. Pharmacists were then asked if they would change any of their current practice and interaction with older adults and how satisfied were they of the game. Pharmacists' reflections were recoded and content analysis 
Table 1. Pharmacists' reflection following completion of the geriatric medication game

\begin{tabular}{ll}
\hline Learning objective & Reflection questions \\
\hline $\begin{array}{l}\text { Raise pharmacists' perceptions and awareness toward older } \\
\text { adults physical and sensory disabilities }\end{array}$ & $\begin{array}{l}\text { What were the feelings or emotions that you experienced while } \\
\text { playing the game? } \\
\text { Your attitude towards elderly patients changed from playing the } \\
\text { game? How? }\end{array}$ \\
\hline $\begin{array}{l}\text { Identify limitations occurring as a result of disabilities in older } \\
\text { adults }\end{array}$ & $\begin{array}{l}\text { Do you think older adults require more time and attention while } \\
\text { counseling? }\end{array}$ \\
\hline $\begin{array}{l}\text { Familiarize pharmacists with older adults' barriers faced when } \\
\text { seeking medical advice }\end{array}$ & $\begin{array}{l}\text { What did you learn about the elder experience from playing this } \\
\text { game? }\end{array}$ \\
\hline Practice empathy towards older adults & $\begin{array}{l}\text { What was the most exercise (disability) that was hardest on you? } \\
\text { Did you remember any family member or patient in particular } \\
\text { playing this game? }\end{array}$ \\
\hline $\begin{array}{l}\text { Change common practice accordingly } \\
\text { How would this game change your future practice as a community } \\
\text { pharmacist? } \\
\text { Can you share a story from the past with an older adult and wish } \\
\text { you could have handled it better? }\end{array}$ \\
\hline
\end{tabular}

Table 2. Predominant* themes expressed by pharmacists upon reflection $(N=9)$

\begin{tabular}{l} 
Theme \\
\hline Theme 1: felt frustrated and helpless while playing the game
\end{tabular}

* For a theme to be considered predominant a 50\% minimum threshold of pharmacist comments must be reached on the same aspect.

was performed to identify grounded theories. Following the completion of each task, pharmacists were asked to share their reflection. To assure the game's objectives are being covered, we asked 1-3 questions from the ones listed in (Table 1). At the end of the session, pharmacists were rewarded with a plant that had a sentimental quote; which was: "Elders are the root of society," take care of them.

\section{Assessment and Results}

A total of 9 community pharmacists completed both physical and sensory tasks each. The pharmacists were divided around 4 round tables. Each table with a total of
2 pharmacists and 1 kit. Themes were predominant, with $50 \%$ occurrence or more; and are listed in (Table 2). Overall, all participating community pharmacists felt frustration and helplessness playing the game (100\%), followed by feeling empathy, sympathy, and or compassion towards older adults limited by any sensory or physical disability or both. Pharmacists also stated that they became more aware of the extra time and guidance needed with older adults in order to properly counsel them and make sure they understand the proper use of their medications, labels, and any additional remarks (88.89\%).

Moreover, over 3 quarter of attended community pharmacists (77.78\%) realized how disabling and difficult 
living with chronic disease(s) could be particularly with advanced age as well as needed improvement of common perceived attitude towards older adults. They also felt the need to assess if patient need any assistance according to any perceived disability or chronic disease is present that can limit certain counseling points; such as splitting pills, using a spoon, reading a small label, reading instructions, or even opening a medication bottle.

Furthermore, just over half community pharmacists (56.3\%), stated the need of reviewing Beer's criteria and educating themselves more about older adults and also wished they had more training on geriatrics during pharmacy school. Finally, all 9 pharmacists loved the exercises and wished to have more similar simulation games to raise awareness on any health-related or populationbased issue. All rated their satisfaction rate as 5 (from a scale of 0 to 5 ).

\section{Discussion}

Our study is the first to assess the impact of a simulated game; particularly the geriatric medication game on community pharmacist's awareness on the day-to-day challenges faced by older adults when visiting the pharmacy. Pharmacist play a vital role in geriatrics care, particularly in the community pharmacy, where they dispense prescription medications to older adults and prescribe an OTC medication for them [15].

The increasing number of older adults in Saudi Arabia demands not only educating our future pharmacists on guidelines; such as Beer's criteria, but also in building empathy and understanding of possible disabilities in this population in order to serve them better. Many steps are deemed necessary in the dispensing cycle; and if one of them is missed, potential medication errors or harm may rise.

Physical and sensory losses in older adults due to aging and as a result of a chronic disease; decreases mobility, independence, and overall quality of life [16]. In our study, $77.78 \%$ felt the need to double check with older adults if they had any limitations to properly educate them on their medications.

For example, an elderly patient with hearing disability may have poor understanding of the proper use of their medication. Moreover, any changes to the instructions written on a label may not be made if we do not make sure they understood those changes carefully. Writing any additional instructions can be of added benefit in these situations [17].
On the other hand, older adults with vision disability could also face harmful errors if not properly educated on their medications. It is known that older adults can find it difficult to read small prints in labels, therefore, assessing their ability in reading the label and helping them chose an appropriate OTC is recommended [18].

Finally, physical barriers in the elderly such as arthritis, and tremors, may also make it hard for the patient to take his/her medications. Making sure the bottle is not "child protected" and double checking if he/she can easily access and administer his/her medication is an important role for the community pharmacist [16].

Similar to previous studies done in the US, using the geriatric medication game or a modified form of it; feeling helpless and frustrated was the first thing reflected by all our participants. The game also helped provoke empathy and sympathy towards older adults, and these were also described previously $[9,13,14]$. Having their colleague as the pharmacist and changing roles helped grasping older adult's - with disability - needs, and as a result $88.89 \%$ became more aware of the needed time and guidance to older adults when dispensing their medications, counseling, and helping in choosing an OTC medication.

In the US, it is estimated that $90 \%$ of older adults take a weekly medication, and over $55 \%$ of women and $44 \%$ of men are on 5 medications or more [19]. Although no such data in Saudi Arabia, it is known that with advanced age, chronic diseases may lead to complications and this only adds to the number of medications prescribed and obtained from community pharmacies.

Moreover, $44.45 \%$ wished they had more training on geriatrics during pharmacy school. Although the geriatric course is available in multiple pharmacy schools, further training is necessary for present community pharmacists. Such simulation games may be thought-provoking and may provide improved understanding; such as the scenarios explained in this paper. The positive outcome of this game provides a strong support for future implementation of it and other simulation games. These games can provide further refinement of knowledge and application in pharmacy schools and in real life.

Based on the results of this study, incorporation of the geriatric medication game to community pharmacists would improve the attitude and raise awareness on the difficulties faced by older adults taking their daily medications. The exercise and scenarios selected in this analysis were simple, yet stimulated so much feelings and understanding towards the elderly, in each participant. Although the number of pharmacists was low, a $100 \%$ 
satisfaction rate was noted, paving the way for similar gamified workshops.

Finally, although this workshop focused on challenges and limitations faced by the elderly. The results can be extrapolated to other patient populations with disabilities that can raise pharmacist's empathy and sympathy. There were some limitations to this study, especially related to the methods used to evaluate its impact. First, we did not use a control group to compare outcomes, and there was no pre- and post-survey to assess attitude and awareness. Second, it was hard to gather a bigger number of community pharmacists in 1 room. Although participation was voluntary, we could have made their participation more attractive by offering continuous education hours.

Future studies on a bigger scale and across the country can further assess attitude and perspective of such workshops on practice. We recommend implementing the gamification of simulation workshops starting from pharmacy schools and reinforcing by community awareness campaigns periodically; to involve a bigger number of pharmacists across the country.

\section{Conclusion}

Simulation games are a great way to strengthen awareness and change practice accordingly. The geriatric game was a fun and educational tool that helped stimulate common scenarios between an elderly patient and a community pharmacist. Pharmacists improved their awareness and attitude towards the elderly and reported a positive perceived value of this learning activity. The geriatric medication game could be adapted to other healthcare practitioners and we believe if it was done interprofessionally the impact will be even greater. This paper proposes a new channel for integrating simulation within the pharmacy school curriculum.

\section{Acknowlegdement}

I would like to acknowledge the pharmacy interns: Fatma AlHaity, Lana Fagih, Murooj Salamah, Lina Moumenah, Bayader Kalkatawi, and Atheer Maghrabi; who helped organize the kits, facilitated the session and documented pharmacists' reflections. Thank you for your valuable contributions. I would also like to thank $\mathrm{Al} \mathrm{Nah-}$ di pharmacy chain that welcomed the idea of the game, gathered the community pharmacists, and allowed us to use their venue for this educational game.

\section{Statement of Ethics}

The paper is exempt from Ethical Committee approval since it was a quality improvement project and did not collect any personal or identifiable data.

\section{Conflict of Interest Statement}

Authors declare that there is no conflict of interest.

\section{Funding Source}

The authors have no funding to report.

\section{References}

1 United Nations, Department of Economic and Social Affairs, Population Division. World population ageing: 2017 highlights. 2017. Available from: https://www.un.org/ en/development/desa/population/publications/pdf/ageing/WPA2017_Highlights.pdf Accessed 2021 January 6.

2 Qato DM, Alexander GC, Conti RM, Johnson M, Schumm P, Lindau ST. Use of prescription and over-the-counter medications and dietary supplements among older adults in the United States. JAMA. 2008;300:286778.

3 Yegenoglu S, Baydar T. Information and observations of community pharmacists on geriatric patients: a qualitative study in Ankara city. Turk J Geriatr Geriatri Derg. 2011; 14.
4 Pelicano-Romano J, Neves MR, Amado A, Cavaco AM. Do community pharmacists actively engage elderly patients in the dialogue? Results from pharmaceutical care consultations. Health Expect. 2015; 18: 1721-34.

5 Correia C, Lopez KJ, Wroblewski KE, Huisingh-Scheetz M, Kern DW, Chen RC, et al. Global sensory impairment in older adults in the United States. J Am Geriatr Soc. 2016;64: 306-13.

6 Boland B, Guignard B, O, Lang PO. Application of STOPP/START and Beers criteria: compared analysis on identification and relevance of potentially inappropriate prescriptions. Eur Geriatr Med. 2016;7:416-23.

7 Odegard PS, Breslow RM, Koronkowski MJ, Williams BR, Hudgins GA. Geriatric pharma- cy education: a strategic plan for the future. Am J Pharm Educ. 2007;71:47.

8 ElDesoky ES. Pharmacokinetic-pharmacodynamic crisis in the elderly. Am J Ther. 2007; 14:488-98.

9 Evans S, Lombardo M, Belgeri M, Fontane PE. The geriatric medication game in pharmacy education. Am J Pharm Educ. 2005;69:304.

10 Marte AL. How does it feel to be old? Simulation game provides 'into aging' experience. J Contin Educ Nurs. 1988;19:166-8.

11 Schmall V, Grabinski CJ, Bowman S. Use of games as a learner-centered strategy in gerontology, geriatrics, and aging-related courses. Gerontol Geriatr Educ. 2008;29:225-33.

12 Bonstelle SJ, Govoni AL. Into aging: exploring aging through games. Rehabil Nurs. 1984;9: 23-7. 
13 Oliver CH, Hurd PD, Beavers M, Gibbs E, Goeckner B, Miller K. Experiential learning about the elderly: the geriatric medication game. Am J Pharm Educ. 1995;59:4.

14 Chen AMH, Plake KS, Yehle KS, Kiersma ME. Impact of the geriatric medication game on pharmacy students' attitudes toward older adults. Am J Pharm Educ. 2011;75:158.

15 Alanazi AS, Alfadl AA, Hussain AS. Pharmaceutical care in the community pharmacies of Saudi Arabia: present status and possibilities for improvement. Saudi J Med Med Sci. 2016; 4:9-14.
16 Grimmer M, Riener R, Walsh CJ, Seyfarth A. Mobility related physical and functional losses due to aging and disease: a motivation for lower limb exoskeletons. J Neuroeng Rehabil. 2019;16:2.

17 National Institute on Aging. Hearing loss: a common problem for older adults. Available from: https://www.nia.nih.gov/health/hearing-loss-common-problem-older-adults Accessed 2021 January 8.
18 Leat SJ, Krishnamoorthy A, Carbonara A, Gold D, Rojas-Fernandez C. Improving the legibility of prescription medication labels for older adults and adults with visual impairment. Can Pharm J. 2016;149: 174-84.

19 Tamez-Peña AL, Tamez-Pérez HE, PeñaLazo A, Ocampo-Candiania J, Torres-Pérez JF. Use of medications on the elderly. Med Univ. 2014;16:199-206. 